\title{
AIAA-2002-4206 \\ Oxidizer Selection for the ISTAR Program (Liquid Oxygen versus Hydrogen Peroxide)
}

\section{Jason Eugene Quinn}

NASA Marshall Space Flight Center, Huntsville, Alabama
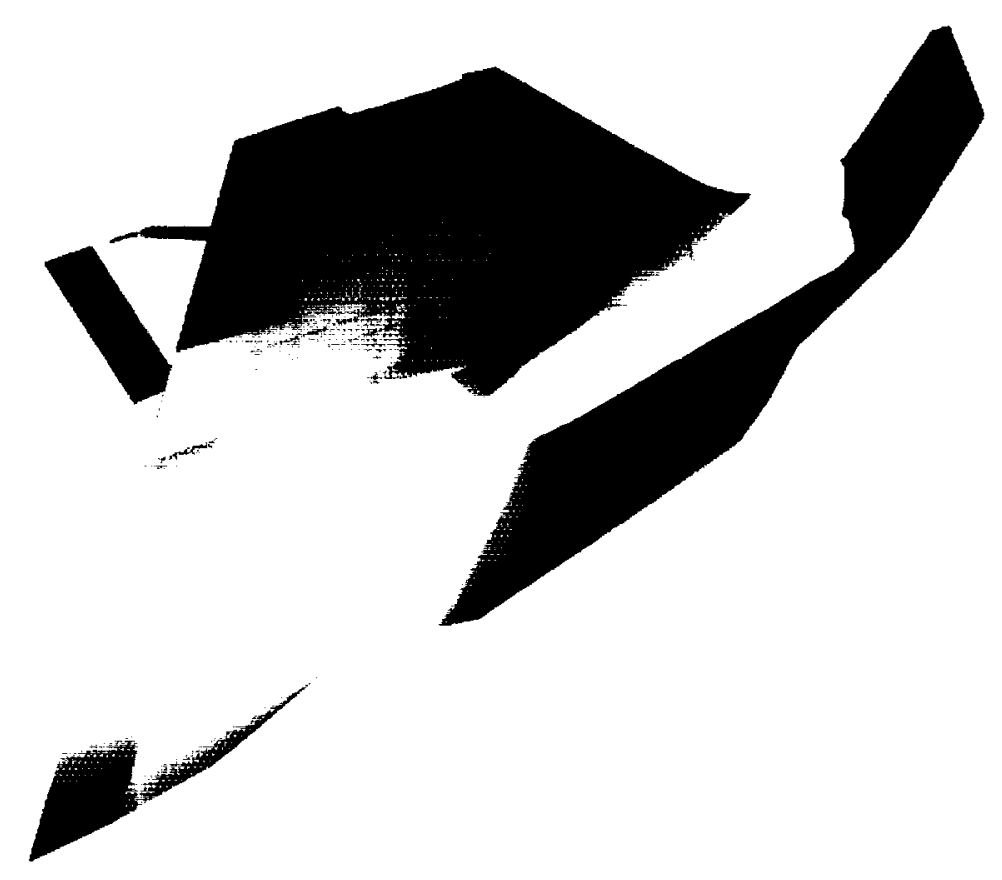

AIAA/ASME/SAE/ASEE $38^{\text {th }}$ Joint Propulsion Conference and Exhibit 7-10 July 2002

Indianapolis, Indiana 


\title{
OXIDIZER SELECTION FOR THE ISTAR PROGRAM (LIQUID OXYGEN VERSUS HYDROGEN PEROXIDE)
}

\author{
Jason Eugene (Quinn, NASA Marshall Space Flight Center, Huntsville, Alabama
}

\begin{abstract}
This paper discusses a study of two alternate oxidizers, liquid oxygen and hyl irogen peroxide, for use in a rocket based combined cycle (RBCC) demonstrator vehicle. The flight vehicle is b.ıselined as an airlaunched self-powered Mach 11.7 to 7 demonstration of an RBCC engine through all of its air breathing propulsion modes. Selection of an alternate oxidizer has the potential to lower overall vehicle size, system complexity / cost and ultimately the total program risk. This trade study examined the oxidizer selection effects upon the overall vehicle performance, safety and operations. After consideration of all the technical and programmatic details available at this time, $90 \%$ hydrogen peroxide was selected over liquid oxygen for use in this program.
\end{abstract}

\section{Introduction}

The Advanced Space Transportation Program at NASA Marshall Space Flight Center has assembled a government / industry team to cunduct the system development and ground test of a RBCC propulsion system (and potentially flight). Government team membership includes participants from several NASA centers: Dryden Flight Test Center, Glenn Research Center, Langley Research Center, Marshall Space Flight Center and Stennis Test ('enter. The primary industry team member is the Rocket Based Combined Cycle Consortium $\left(\mathrm{RBC}^{3}\right)$, which includes Boeing Rocketdyne, Gencorp Aerojet and United Technologies Pratt \& Whitney'. Additional industry team members include Boeing for vehicle activ ities and several other companies.

Current plans for the propulsion system development and ground test of the RBCC engine system are funded through NAS $\triangle$ MSFC as the Integrated System Test of an Airbreathing Rocket (ISTAR) program. The primary ISTAR program objective is to develop a propul sion system, which would be capable of powering a flight demonstrator vehicle from launch off a B-52 iircraft (approximately Mach 0.7) up to scramjet speed; of about Mach 7. This

This material is declared a wolk of the U.S. Government and is not subject 11 copyright protection in the United States. flight velocity range would demonstrate all of the RBCC engine operational modes: Air Augmented Rocket (AAR), Ramjet and Scramjet. Although only the ISTAR propulsion system development and the initial ground test program is currently funded, due to the tightly integrated nature of a hypersonic vehicle, initial demonstrator vehicle design is being performed to define the propulsion system requirements.

Initial conceptual design of hypersonic vehicles requires the designer to assume many system characteristics such as propellants, thrust, and vehicle size to satisfy mission objectives. The designer uses their experience on previous similar vehicles to decide what to select. Although these initial "guesses" are often quite good, they can limit the ability of the design if one does not go back and check their assumptions. For example, one of the first items to decide upon is the propellant combination that the system will use. Typically the designer would select the highest ISP combination propellant, but this might not be the best selection for non-orbital missions. A lower performing (in terms of ISP) propellant combination that is more dense or non-cryogenic could result in a smaller, lower cost, more reliable or more operable vehicle system.

The ISTAR program has conducted several trade studies on the "right" propellant combination to select for this program. Selection of a hydrocarbon (HC) as the fuel for the ISTAR program over liquid hydrogen, although an interesting trade study, will not be discussed in this paper. Once the decision to use a hydrocarbon fuel was made, there were still at least two oxidizers that could potentially meet the system requirements: liquid oxygen (LOX) and hydrogen peroxide (HTP). The purpose of this paper is to detail the trades that the ISTAR program went through in selecting between these two oxidizers.

\section{$\underline{\text { General Considerations }}$}

Most of the rocket industry moved away from the use of hydrogen peroxide in the early 1960's for several reasons: large all rocket propulsion systems went to LOX due to the increase in performance (ISP), long term storage users went to NTO/MMH and monopropellant customers switched to Hydrazine. The recent resurgence of interest in HTP in applications where LOX would typically be used is in part due to the realization that higher ISP is not the entire story. Higher propellant density and storability can, in some 
cases, make HTP a better choics than LOX. This is especially true for systems that luave aerodynamic drag losses or are severely volume c(instrained ${ }^{2}$; ISTAR has large aerodynamic drag (relative to an all rocket) due to its airbreathing trajectory and se vere volume constraints due to its slender hypersonic shipe.

Hydrogen Peroxide has physical properties very similar to water (i.e. density, color, viscosity, etc.) ${ }^{2}$. The primary exception is that the molecular structure is only meta-stable and will exothermically decompose from $\mathrm{H}_{2} \mathrm{O}_{2}$ (basically a water mulecule with an extra oxygen atom attached) at some rate to a water molecule, oxygen and energy. This hot steam and oxygen $\left(1300^{\circ} \mathrm{F}\right)$ can then be expanded out a nozzle as a monopropellant thruster or the hot oxygen can be combusted with a fuel. In either case the hydrogen in HTP is tightly bound in a water molecule and is not combusted. When the concentuation is quoted as $90 \%$ that means $90 \%$ Hydrogen Peroxide in solution with $10 \%$ water and traces of stabilizers. In a compatible storage container $90 \%$ HTP has been observed to decompose at less than $1 \%$ per decade but in the presence of a catalyst HTP can be caused to decompose extremely rapidly? ${ }^{?}$. HTP has been used as a turbomachinery drive gas in many systems: V-2, X-1, Redstone, Jupiter, Centaur, Vikng, X-1 and the X-15

2,4. HTP has also been used as the primary oxidizer (bipropellant) in many propulsion ystems: Me 163 Komet, Gamma 201/301, AR ssries of rocket engines, LR-40 and others ${ }^{2.4 .5 .6}$ (as the mijority of these flight systems used $90 \%$ HTP it was the first concentration considered). HTP physical properties of interest are compared to LOX in Table 1 and density compared to several propellants in Figure 1.

Figures $2 \& 3$ show the id al specific impulse and density specific impulse of LOX and several concentrations of HTP with hycrocarbon fuel. Density specific impulse is the density of the propellant combination (i.e. bulk density or $\rho_{\text {mixture }}$ ) multiplied by the specific impulse. It is often used to select propellants when volume considerations are taken into account. $90 \%$ HTP is only $15 \mathrm{lb} / \mathrm{ft}^{3}$ denser than LOX, but the peak ISP occurs at a mu h higher mixture ratio (typically 2.6 for LOX/HC versus 7 for $\mathrm{HTP} / \mathrm{HC}$ ). This results in a much higher bulk density for HTP/HC over LOX/HC. The argument can be made that for a sufficiently low mission velocity change $(\Delta V)$, a lower performing (in terms of ISP) denser propellant combination would yield a smaller propellant volume required. Typically we assume that the mission cost is roughly proportional to vehicle size - thus the lower performing propellant would be a "better" choice.

\section{Generic Comparison}

In order to determine if our vehicle would be "better" with a particular propellant combination we can calculate the propellant volume required for our given mission $\Delta V$ and assumed mission averaged effective specific impulse $\left(\mathrm{I}^{*}\right)^{3}$.

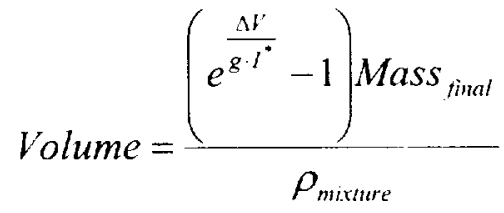

In the case of ISTAR our initial vehicle utilized the rocket thrusters only for AAR Mode which is Mach 0.7 (air drop) to Mach 3.0-4.0 where the rocket is to be turned off (see Figure 10) and the engine transitioned to Ramjet mode. The vehicle is assumed to perform identically for either oxidizer above Mach 3.0-4.0 as Ramjet/Scramjet modes only use tanked $\mathrm{HC}$ fuel and air. For a first cut analysis assume that the mass of the vehicle is the same at the end of AAR mode (Mach 3.04.0) for either oxidizer (which approximately corresponds to $\Delta V$ of 2000 to $4000 \mathrm{ft} / \mathrm{sec}$ ). With this assumption we can plot, Figure 4 which shows the propellant volume required with either oxidizer for the Air-Augmented Rocket (AAR) mode of operation. The point made by Figure 4 is that below a mission $\Delta V$ of approximately $4000 \mathrm{ft} / \mathrm{sec} \mathrm{HTP} / \mathrm{HC}$ will require less propellant volume than $\mathrm{LOX} / \mathrm{HC}$ for the I* value assumed. These $\mathrm{I}^{*}$ values were generated from our three degree-of-freedom trajectory model. If you assume the same total propellant volume is available with either oxidizer, then one can plot Figure 5 which shows the I* required for each propellant combination at several values of mission $\Delta \mathrm{V}$. For example, Figure 5 shows that for a $\Delta V$ of $2000 \mathrm{ft} / \mathrm{sec}$ if the $I^{*}$ for the LOX/HC vehicle is $240 \mathrm{sec}$ than the I" of the HTPHC vehicle needs to be $196 \mathrm{sec}$ or higher to have the same or less propellant volume required. From these graphs we can conclude that below $\sim 4000 \mathrm{ft} / \sec \Delta \mathrm{V}$ a $90 \%$ $\mathrm{HTP} / \mathrm{HC}$ thruster will require less tank volume than a LOX/HC thruster including the effect of the additional mass of the more dense propellant provided the $I^{*}$ of the HTP/HC vehicle in AAR mode exceeds the I* of the $\mathrm{LOX} / \mathrm{HC}$ value given in Figure 5.

\section{Background - Initial System Definition}

In order to understand the conclusions drawn from the trades performed some familiarity with the ISTAR vehicle $(\mathrm{X}-43 \mathrm{~B})$ and engine system is needed. The ISTAR vehicle was designed around an existing hypersonic vehicle shape designed for liquid hydrogen which was then modified for our particular mission and propellant combination. Figure 6 shows three views of the current configuration with the propellant tank location/volume emphasized. Generically this 
configuration is a lifting body with external forebody compression, moving cowl flap inlet with fixed internal geometry and external aft expansion.

A generic mission (shown in Figure 7) begins when the ISTAR vehicle is dropped from the NASA B-52 at Mach 0.7 and 40,000 ft, accelerites to approximately Mach 7 at $90,000 \mathrm{ft}$ before shutling down the engine and gliding back for re-use. Aftcr being dropped from the B-52 vehicle the vehicle frecfalls for a few seconds before starting the rocket thrusters and accelerating in Air-Augmented Rocket (AAR) mode. In this propulsion mode the rocket thrusters are firing at full thrust and additional fuel is injected to burn with the incoming air. As the vehicle ac elerates through Mach 3-4 the rocket thrusters are turnid off and the vehicle continues to accelerate in Ramjet mode. Upon reaching Mach 6-7 the vehicle transitions fully into Scramjet mode before shutting down - completing the demonstration of all the airbrearhing propulsion modes and the transitions between theri for an RBCC engine.

The ISTAR team baselined a simple engine system based upon the type used in the X-15 (and many other previous systems) using a high-pressure tank of HTP to drive the fuel and oxidizer pump. The functional schematic for this type of systen with either LOX or HTP as the primary oxidizer is shown in Figures 8 \& 9. This type of system was selected to keep the development costs of the engint system as low as possible and still allow the RB C C multi-mode operation. The ISTAR program: is focused on engine flowpath performance throughout the mission trajectory, especially in mode transitions, and not in engine system development. Dise to flight experience with many previous programs, $10 \%$ HTP was baselined to be used for the turbine drive $z$ as rather than a higher concentration of HTP, which $\mathrm{m} / \mathrm{ght}$ have increased performance (and increased risk.).

Figure 8 shows the LOX/HC en rine system and all of the functional components required to operate in the engines different modes. As previously stated the system uses a high pressure HT' tank to provide hot gas to the turbine drive (yellow. As this tank is not linked to the main oxidizer tank we can run just the fuel pump (no rocket thruster oxidizer needed in Ram / Scramjet modes). Figure 8 shows the vehicle systems in the top left portion of the figure with the main fuel tank, high-pressure HTP tank and main LOX tank along with the gray purge gas tanks. I he top right portion of the figure shows the systems required on the carrier aircraft (B-52) primarily the LC X top off tank (note the purge gas supply was the same for both the HTP and LOX systems and is not shown. Finally the bottom left side of figure 8 shows the engine system components including the ignition system (baselined combustion wave ignition [CWI] for the $\mathrm{LOX} / \mathrm{HC}$ system). The components highlighted with a red background are those that are different between the LOX and the HTP system - note that the primary difference between figures 8 and 9 is the LOX top-off system and the ignition system (CWI for LOX/HC and catalyst packs for the HTP/HC system)

Figure 9 shows the HTP/HC engine system. This system is very similar to the LOX system but replaces the CWI system with a catalyst pack arrangement to provide auto-ignition in the rocket thrusters and doesn't require LOX top-off. These two changes reduced the number of fluids on the vehicle and the complexity of the functional schematic considerably.

\section{Detailed Oxidizer Trade}

The ISTAR engine system was originally baselined to be LOX/HC as these propellants are familiar and were believed to provide enough performance without the severe volume penalty of $\mathrm{LH} 2$. Prior to the initial formation of the $\mathrm{RBC}^{3}$ team a conceptual trade study on the propellant selection indicated that replacing LOX with $90 \%$ HTP would allow a smaller propellant volume to complete the mission (Mach 0.7 to 7 ). This rudimentary study results and several discussions between NASA and $\mathrm{RBC}^{3}$ provided motivation to complete a comprehensive trade study examining in detail the system impacts of switching the oxidizer from LOX to HTP.

The oxidizer trade study team brainstormed a detailed list of the important criteria that were judged to affect the entire system design. Table 2 shows these criteria grouped into five sections: Safety, Programmatic, Mission Success/Engine System Design, Mission Success/Vehicle Integration and Operations. Within these five sections the criteria were also grouped into categories (i.e. vehicle design impacts). Each of the five sections was assigned a weighting factor, which attempted to capture program management's preference or importance level for that section. Each criteria was to be assigned a 1, 3 or 9 score for how beneficial an oxidizer was to the system on this criteria. Scores were then combined with the weighting to produce a single ranking for each oxidizer.

Each of the criteria was assigned a criteria owner(s) who was responsible for investigating the criteria, selecting a score and providing a group presentation to back up that score. The criteria owner(s) then presented the score to the entire trade study team for discussion and the trade team selected a final consensus score. 
The process of assigning a team : onsensus score required all of the team member to become educated about the criteria being considered. This educational process enhanced the team objectivity and the entire trade study. Criteria owners were selected from the $\mathrm{RBC}^{3}$ team members, NASA centers and Boeing. The entire team leaned heavily on the recent operational experience with both LOX and ITP at NASA STENNIS and the flight operati ins experience (both recent and historical) at NASA J)RC.

Very early in this trade study th: trade study team explored the potential for use of $98 \%$ HTP rather than $90 \%$ HTP. $98 \%$ HTP was consitered as there was additional performance over $90^{\circ}$ is HTP. However, for this low $\Delta \mathrm{V}$ mission, the additicnal unknowns and development risk with $98 \% \mathrm{HT}^{\prime}$ ' was judged to be not worth this small performance bowst. The remainder of the trade study was performed cumparing $90 \%$ HTP to LOX only.

\section{$\underline{\text { Safety }}$}

This category was assigned the heaviest weight at $25 \%$ (see Table 2) but was the least controversial in team discussions. Peroxide was judged to be safer overall than LOX primarily due to the need for a LOX top-off system to transfer LOX from th: B-52 to the X-43B vehicle (similar to how the $\mathrm{X}-15$ worked). This LOX top-off system would have had to operate on the manned carrier aircraft during the entire flight up to $X$ 43B drop. HTP has a higher de rree of risk with leaks and spills in the engine / vehick system but was considered safer than LOX when considering the entire propellant handling process. Tlıse two criteria balanced one another out in the scoring leaving HTP scoring safer than LOX for the ISTAR project.

\section{$\underline{\text { Programmatic }}$}

The next three categories were considered to be of equal importance and were all given the same weight of $20 \%$. The programmatic criteris required much discussion and work before the team could agree on a consensus score in the three are is of Schedule, Cost and Risk. After significant discussion the schedule for either oxidizer was determined to be equivalent provided additional money was made available and $i$ or more risk was accepted for HTl' The initial development cost with HTP wa considered to be significantly more (on the order of several million dollars) primarily due to the need to develop the HTP cooled thruster. Considering the entire system HTP would save significant dollars (\$3-5 million) due to not needing a LOX top-off system but the additional cost for facility modification influenced the team to only allot a slight advantage to HTP in facilities / test costs. The final criteria of programmatic risk determined that selecting HTP would add more overall risk to the program. This risk would be primarily in the beginning of the project during the thruster development while selecting LOX would potentially delay the risk of the LOX top-off system to the flight phase of the program.

\section{Mission Success / Engine System Design}

The single most controversial criteria in this oxidizer trade study is the technology readiness level and associated risk in developing the rocket thrusters with either oxidizer including oxidizer cooling. Due to the need to cool the significant surface area of the duct with the fuel being fed to the rocket both the LOX/HC and $\mathrm{HTP} / \mathrm{HC}$ were assumed to use oxidizer cooling of the rocket thrusters.

Selection of LOX allows us the comfort level as the thruster would be similar to existing experience base (combustion chamber parameters) but the requirement for LOX cooling introduces a number of system issues which increase mission success risk. NASA GRC has test fired LOX cooled thrusters, which addressed the majority of the issues with LOX cooling, but they did not address the closed loop issues (cooling LOX was not injected and burned in this test series). The closed loop issues like the two phase regenerative cooling during the start transient is risky and potentially would not be discovered until late in the engine system development. Other potential risks with LOX cooling include freezing of the $\mathrm{HC}$ in the lines and the difficulty of dealing with fuel temperature changes as the vehicle accelerates through the Mach number range.

Selection of HTP limits the material selection of the thruster as many metals (including copper) catylize the decomposition of HTP and are typically not considered for use in HTP systems. After several iterations NASA and $\mathrm{RBC}^{3}$ developed the design for two different rocket thrusters (using 347 stainless steel) each of which was capable of performing the mission with some film cooling. Other difficulties introduced by the selection of HTP is the difficulty of packaging the catalyst packs, and a lower thermal margin in the thruster design. After several meetings on this criterion the team determined that LOX was preferred over HTP in the thruster design.

Pump and Ignition Systems were judged to be of equal level of difficulty. The inherent risk in the system due to the startup / shutdown transient and mixture ratio of the engine is higher for the LOX system (more difficult) primarily due to the need to start the thrusters 
LOX rich and pass through stoic hometric and how the LOX density changes during the start.

The engine system design critera favoring LOX over HTP are: less known issues with the oxidizer that might require development effort (known unknowns), a better current design experience base, higher rocket ISP (small advantage) and likely longer hardware life (primarily due to higher thermal margin in the LOX system). Criteria favoring HTP uver LOX are primarily due to the lower system comple xity. Selection of HTP significantly reduced the engine system complexity in terms of number of propellants and complexity of the ignition system as can be seen in Figures $8 \& 9$. The LOX/HC system shown conceptually in Figure 8 needs an ignition system (CWI) and a I OX top-off system. While Figure 9 shows that the $\mathrm{H}$ [P/HC system uses a catalyst pack for ignition and dcesn't require a LOX top-off system. Also HTP is likely to require less purge gas and no chill preconditioning of the oxidizer hardware.

\section{Mission Success / Vehicle Integration}

Unlike the Engine System Design criteria discussed above all the Vehicle Integration criteria trades favored the selection of HTP over LOX. Due to the wedge shape of hypersonic vehicle resulting in a low available volume for propellant, the propellant tanks are typically required to be integral (the tank is the vehicle). Integral cryogenic LOX tanks have never been developed and were judged to be more difficul than the material compatibility issues with integril tanks for HTP. With these considerations HTP was chviously preferred from a structural criteria.

Examining the engine system p.tckaging and propellant feed system issues introduced via each oxidizer came down to the non-cryogenic nature of HTP removing/reducing the need for vacuum jacketed lines, cryogenic insulation, with the potential for removal of the boost pump (considered part of the vehicle). HTP would still require some thermal management but the non-cryogenic nature was felt to be much easier to deal with.

As previously discussed the higher density of $\mathrm{HTP} / \mathrm{HC}$ in a volume limited, low $\Delta V$ vehicle like $X-43 B$ compensates for the lower ISP of the rocket thrusters. This assumes that the same volume is available for the propellant and the vehicle weight won't change with the higher propellant weight. While the assumption that vehicle weight is relatively constant with propellant weight is valid for this vehicle, the assumption of the same propellant volume availatile is not. LOX would likely require some amount of cryogenic insulation to prevent the formation of ice on the vehicle (also would reduce the amount of top-off needed from $B-52$ ).

Assuming an insulation thickness of 1 to 2 inches yields an amount of insulation equivalent to $10-30 \%$ of the total LOX volume. HTP was preferred over LOX for the vehicle integration performance criteria due to this higher potential volume for propellant.

The remaining vehicle integration criteria dealt with the carrier aircraft. The oxidizer selection was felt to heavily influence the impacts on the carrier aircraft on terms of consumables required to be in-flight transferred. HTP would require only nitrogen (or helium) while LOX was assumed to require a higher amount of nitrogen as well as LOX for top-off and chill down. Additionally the avionics / control onboard the B-52 would be much more critical as it would be a manned system with LOX venting. All of the above considerations resulted in the entire section of the trade matrix associated with vehicle integration to be heavily weighted toward the selection of HTP.

\section{Operations}

Operations had the lowest weighting factor at $15 \%$. This lowest weight does not mean that the team did not consider operations important (it is) but this is an engine system for an X-vehicle only meant for -25 flights. Most of the criteria considered in the operations area favored HTP over LOX with the exception of operational procedures being well established. NASA has had recent experience at STENNIS in the E3 test stand with both LOX and $90 \%$ HTP but LOX procedures are simply better know and more established. HTP was considered to have slightly easier handling than LOX (NASA STENNIS \& DRC experience), easier ground operations with less equipment and less vehicle ground operational difficulties (i.e. simpler setup/servicing).

\section{Summary and Conclusions}

A trade study considering two alternate oxidizers, liquid oxygen or $90 \%$ hydrogen peroxide, for a rocket based combined cycle demonstrator vehicle was completed. This trade study considered the overall system performance from both a technical and programmatic viewpoint, to select the lowest risk solution. Given the limited energy requirement $(\Delta \mathrm{V})$ of the demonstrator vehicle (Mach 0.7 to 7 ), the higher density and mass ratio of $90 \%$ hydrogen peroxide yielded similar vehicle performance when compared to LOX. Additionally, hydrogen peroxide provided system simplification, increased flight safety and packaging advantages. After consideration of the technical and programmatic details, $90 \%$ hydrogen 
peroxide was selected over liqu 1 oxygen for use in the ISTAR program.

\section{References}

1. Faulkner, Robert F., "INTEGRATED SYSTEM TEST OF A $V$ AIRBREATHING ROCKET (ISTAR)," AIAA 2001-1812.

2. Ventura, M. and Mullens, P., "The Use of Hydrogen Peroxide for Propulsion and Power," AIAA 99-28811, June 1999, 19 pgs.

3. Escher, William J. D., Hyde, Eric H. and Anderson, David M., "A User's Primer for Comparative Assessments of All-Rocket and Rocket-Based Combined-Cycle Propulsion Systems for Advanced Earth-to-Orbit Space
Transportation Applications," AIAA 95-2474, July 1995, 22 pgs.

4. Wiswell, R., "X-15 Propulsion System," AIAA 97-2682, July 1997, 18 pgs.

5. Butler, K., "AR2-3 Engine Refurbishment and Gas Generator Testing," AIAA 99-2738, June 1999, 6 pgs.

6. Ventura, M. and Wemimont, E., "History of the Reaction Motors Super Performance 90\% H2O2/Kerosene LR-40 Rocket Engine," AIAA 01-3838, July 2001, 10 pgs.

7. "Hydrogen Peroxide Handbook," AFRPL-TR67-144, July 1967.

8. Kit, Boris and Evered, Douglas S., Rocket Propellant Handbook, The Macmillian Co., New York, 1960.

Table 1: Oxidizer properties compared ${ }^{7,8}$.

Fluid Properties

Boiling Point, ${ }^{\circ} \mathrm{F}$ (extrapolated it $1 \mathrm{~atm}$ for $\mathrm{H}_{2} \mathrm{O}_{2}$ )

Freezing Point, ${ }^{\circ} \mathrm{F}$ ( $\left.1 \mathrm{~atm}\right)$

Bulk Decomposition Temperature, ${ }^{\circ} \mathrm{F}$ (red line)

Density, g/cc $\left(\mathrm{H}_{2} \mathrm{O}_{2} @ 77^{\circ} \mathrm{F}, 1.4 .7\right.$ psia; LOX $\left.@-297^{\circ} \mathrm{F}, 14.7 \mathrm{psia}\right)$

Density, lbm $/ \mathrm{ft}^{3}\left(\mathrm{H}_{2} \mathrm{O}_{2} @ 77^{\circ} \mathrm{F} .14 .7 \mathrm{psia}\right.$;OX $\left.@-297^{\circ} \mathrm{F}, 14.7 \mathrm{psia}\right)$

Heat Sink, BTU/lbm $\left(77^{\circ} \mathrm{F}\right.$ to $2_{2} 50^{\circ} \mathrm{F}$ for $\mathrm{H}_{2} \mathrm{O}_{2} ;-300^{\circ} \mathrm{F}$ to $140^{\circ} \mathrm{F}$ for LOX)

Critical Pressure, psia (estimated for $\mathrm{H}_{2} \mathrm{O}_{2}$ )

Critical Temperature, ${ }^{\circ} \mathrm{F}$ (estim $t$ ted for $\mathrm{H}_{2} \mathrm{O}_{2}$ )

Cost, $\$ / \mathrm{lbm}$

\begin{tabular}{ll}
$90 \%$ HTP & LOX \\
\hline 286.7 & -297.4 \\
11.3 & -362 \\
275 & NA \\
1.387 & 1.14 \\
86.6 & 71.2 \\
114.7 & 178 \\
3556 & 730.4 \\
833 & -181.8 \\
$3-4$ & $.042-.068$ \\
\hline
\end{tabular}


Table 2: Liquid oxygen versus hydrogen peroxide criteria trade matrix.

\begin{tabular}{|c|c|c|c|c|}
\hline \multirow[b]{2}{*}{ Section } & \multirow{2}{*}{ Category } & \multirow{2}{*}{ Criteria } & \multicolumn{2}{|c|}{ Score } \\
\hline & & & HTP & LOX \\
\hline \multirow[b]{4}{*}{ Weinhting Factor- } & \multirow{2}{*}{ Engine/Vehicle } & Test Personnel/Facilities & 1 & 1 \\
\hline & & ISTAR EngineNehicle & 1 & 3 \\
\hline & Handling & Personnel/Hardware & 3 & 1 \\
\hline & Carrier Aircraft & B-52 Crew/Aircraft & 9 & 3 \\
\hline \multirow{2}{*}{ Wvergnimig ranum. } & & 4 & 14 & 8 \\
\hline & Schedule & SSC Ground Test & 9 & 9 \\
\hline \multirow[t]{3}{*}{ Programmatic } & \multirow{2}{*}{ Cost } & Development & 3 & 9 \\
\hline & & Facilities Modifications/Test & 3 & 1 \\
\hline & Risk & Cost \& Schedule (Confidence in) & 3 & 9 \\
\hline Welgnting ractor: & & & 18 & 28 \\
\hline \multirow{10}{*}{$\begin{array}{l}\text { Mission Success / Engine } \\
\text { System Design }\end{array}$} & \multirow{5}{*}{$\begin{array}{l}\text { Tiechnology Development } \\
\text { Level/Risk }\end{array}$} & Thrusters & 1 & 3 \\
\hline & & Pumps & 9 & 9 \\
\hline & & Ignition System & 3 & 3 \\
\hline & & Transient Operations & 9 & 3 \\
\hline & & Known Unknowns & 1 & 9 \\
\hline & Experience Base & Expert Knowledge/Experience & 3 & 9 \\
\hline & \multirow{3}{*}{ Performance } & Engine System Performance & 1 & 3 \\
\hline & & Design Complexity (No. Values, Pumps, etc) & 9 & 1 \\
\hline & & Hardware Life & 3 & 9 \\
\hline & \multirow{3}{*}{ Resources } & Purge Requirements & 3 & 1 \\
\hline \multirow[t]{2}{*}{ Weighting Factor: } & & Chill \& Conditioning & 9 & 1 \\
\hline & & tom- & 51 & 51 \\
\hline \multirow{6}{*}{$\begin{array}{c}\text { Mission Success / Vehicle } \\
\text { Integration }\end{array}$} & \multirow{3}{*}{ Vehicle Design Impacts } & Structural & 3 & 1 \\
\hline & & Engine System Packaging & 3 & 1 \\
\hline & & Propellant Feed System & 3 & 1 \\
\hline & Performance & Fuel Margin Remaining (FMR) & 3 & 1 \\
\hline & Carrier Aircraft & Consumables (Propellant, purge transfer) & 9 & 3 \\
\hline & C arrier Alrcran & Avionics/Control Interface & 9 & 3 \\
\hline Welgnting ractor: & & - & 30 & 10 \\
\hline \multirow{6}{*}{ Operations } & \multirow{3}{*}{ Handling } & Known Hazards & 1 & 1 \\
\hline & & Operational Knowledge/Procedures & 1 & 3 \\
\hline & & Transportaion, Handling, Storage & 3 & 1 \\
\hline & \multirow{2}{*}{ Cround Operations } & Test Operations & 3 & 1 \\
\hline & & Vehicle Ground Operations & 3 & 1 \\
\hline & Logistics & GSE, Expendables, Soft Goods, etc & 3 & 3 \\
\hline & & 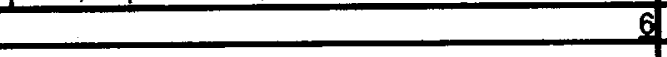 & 14 & 10 \\
\hline & Raw Score & 31 & 127 & 107 \\
\hline \multirow{6}{*}{\multicolumn{2}{|c|}{$\begin{array}{l}\text { Safety } \\
\text { Programmatic } \\
\text { Mission Success/Engine System [ } \text { Yesign } \\
\text { Mission Success/Vehicle Integration } \\
\text { Operations }\end{array}$}} & & 3.5 & 2.0 \\
\hline & & & 3.6 & 5.6 \\
\hline & & & 10.2 & 10.2 \\
\hline & & & 6.0 & 2.0 \\
\hline & & & 2.1 & 1.5 \\
\hline & & d Score & 126 & 106 \\
\hline
\end{tabular}




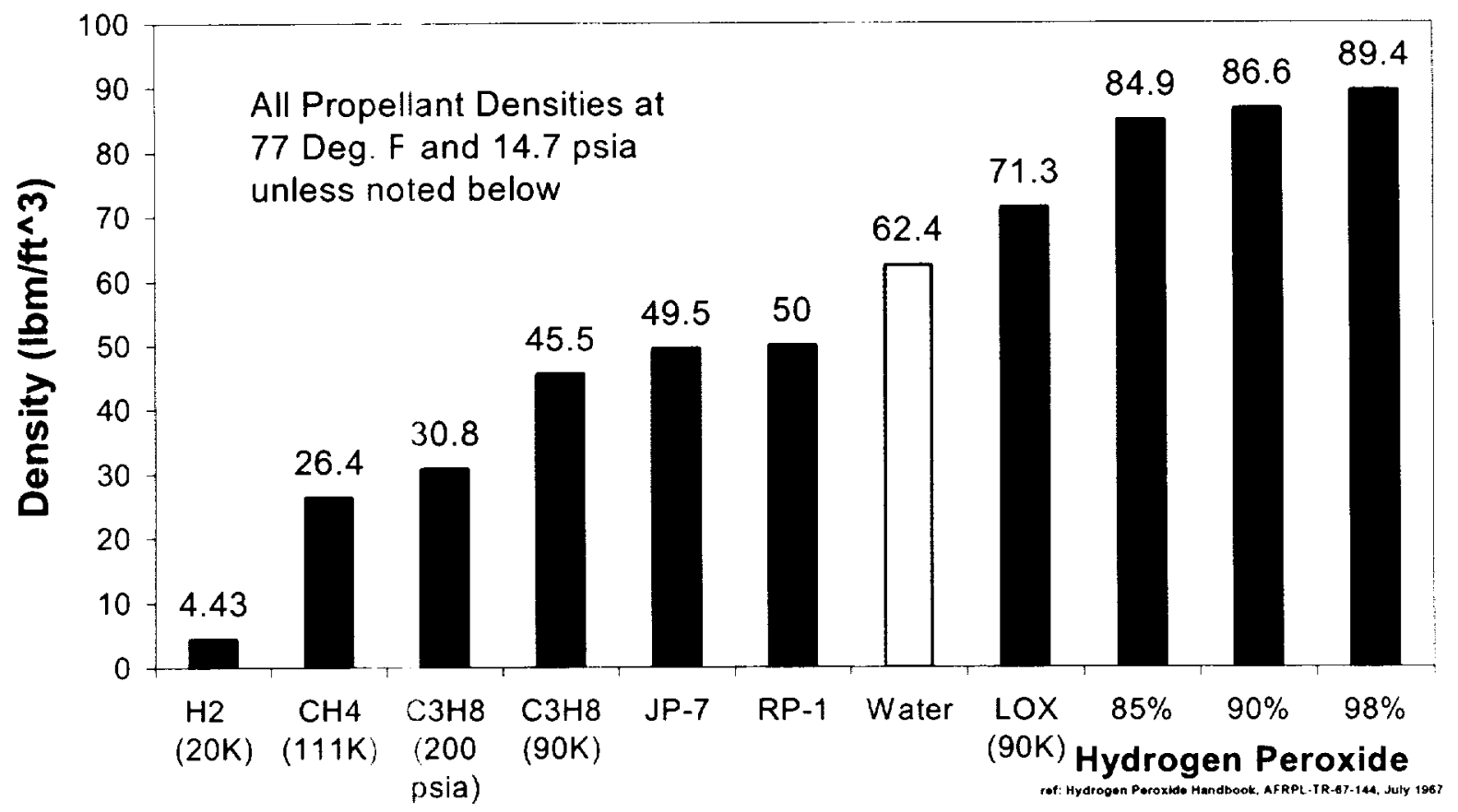

Figure 1: Densities of various propellants compared ${ }^{7,8}$.

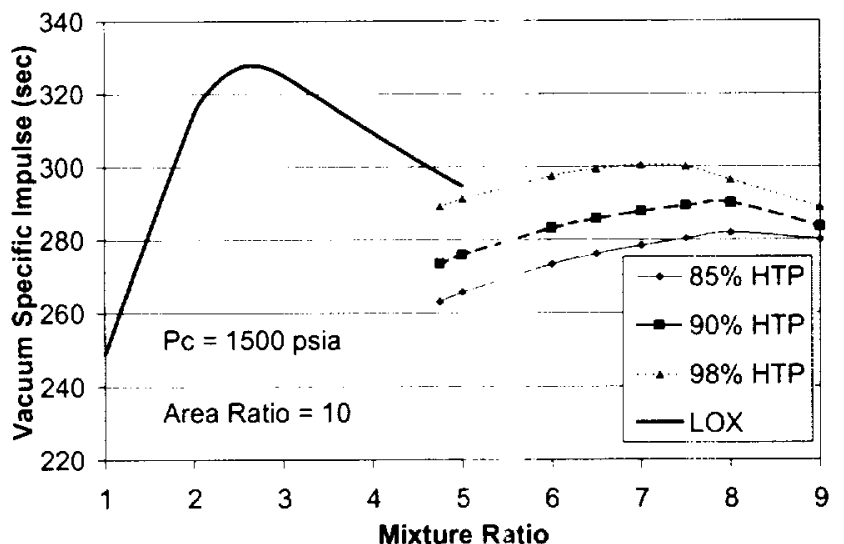

Figure 2: Ideal vacuum specific impulse for hydrocarbon (HC) fuel and various oxidizers.

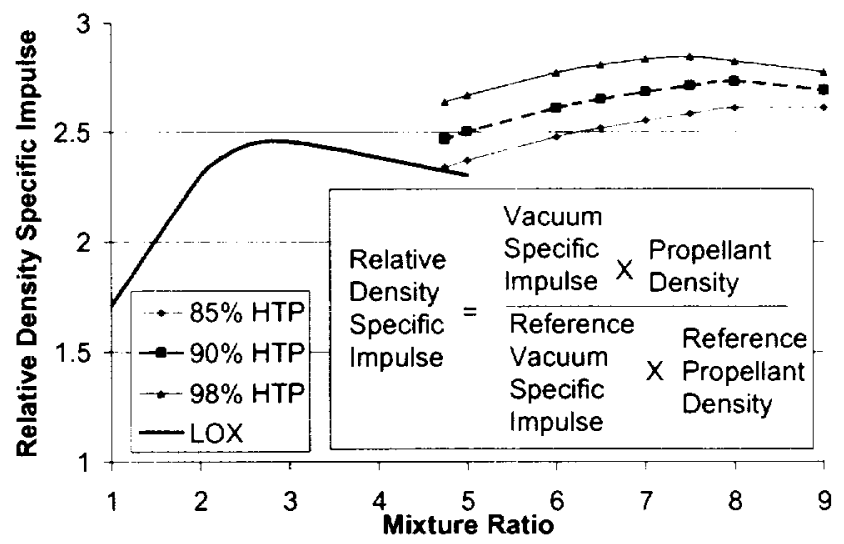

Figure 3: Ideal relative density specific impulse for $H C$ and various oxidizers, (note reference ISP $=$ $417.2 \mathrm{sec}$, reference density $=20.3 \mathrm{lbm} / \mathrm{ft}^{\wedge} 3$ ). 


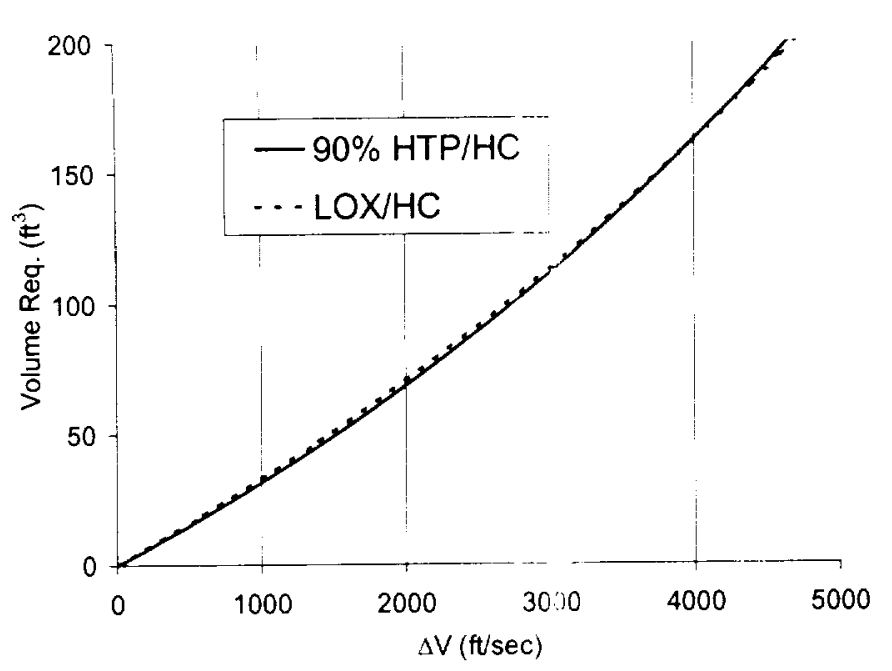

Figure 4: Propellant volume required on $\mathrm{X}-43 \mathrm{~B}$ for oxidizer selected plotted again st mission $\Delta V$.

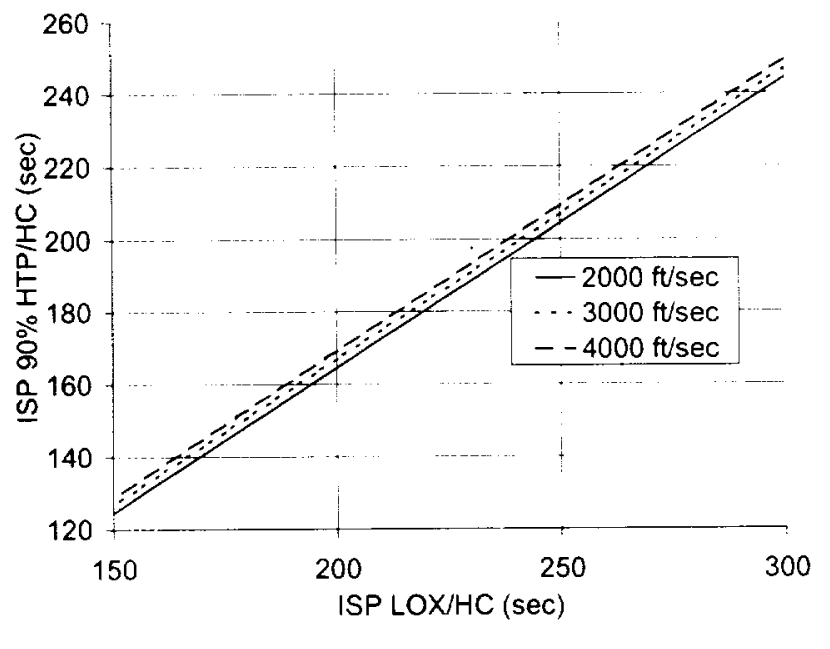

Figure 5: ISP required at given $\Delta V$ for equal propellant volume with either oxidizer.

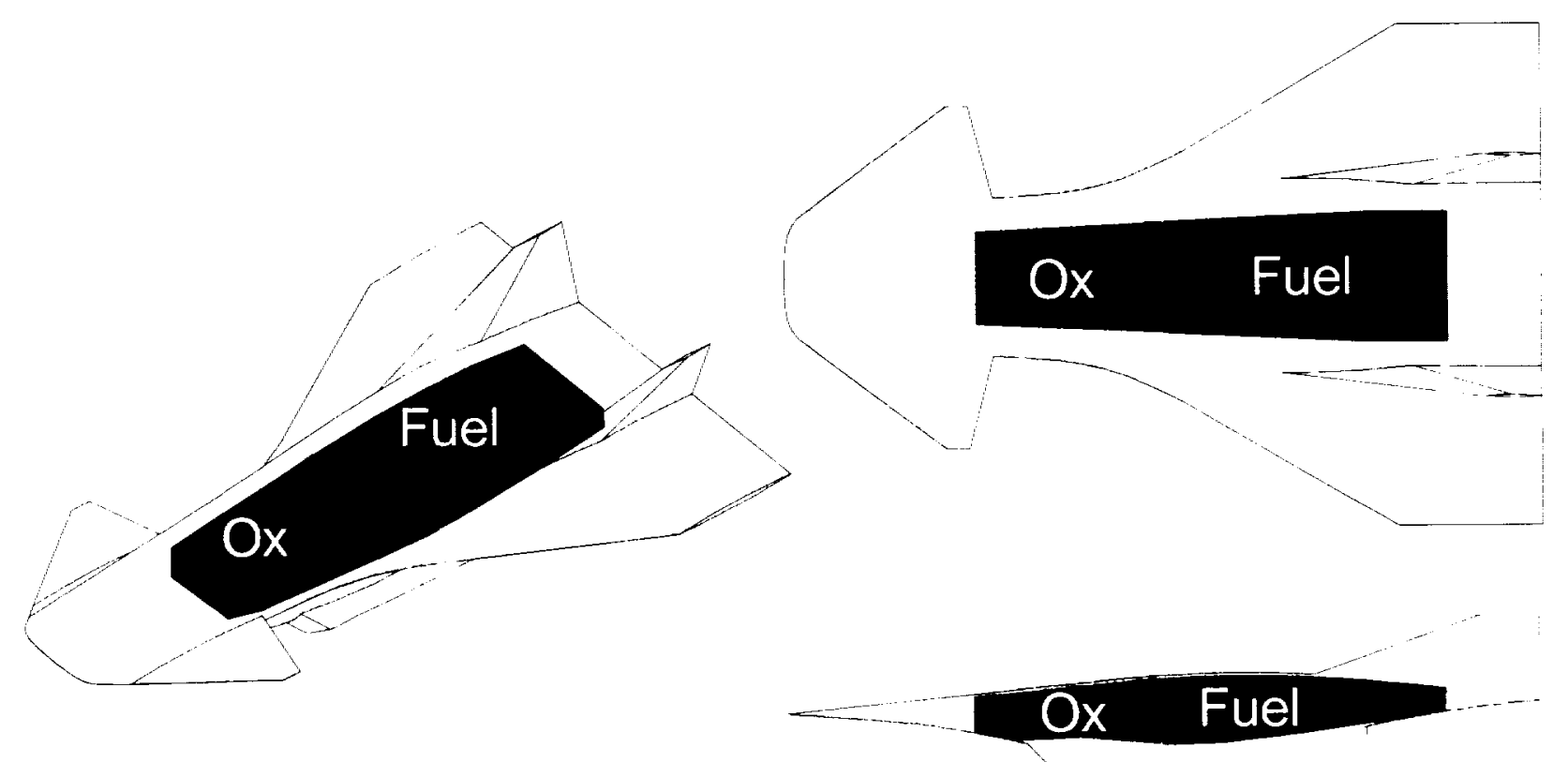

Figure 6: X-43B RBCC vehicle with oxidizer and fuel tank volume / locations shown. 


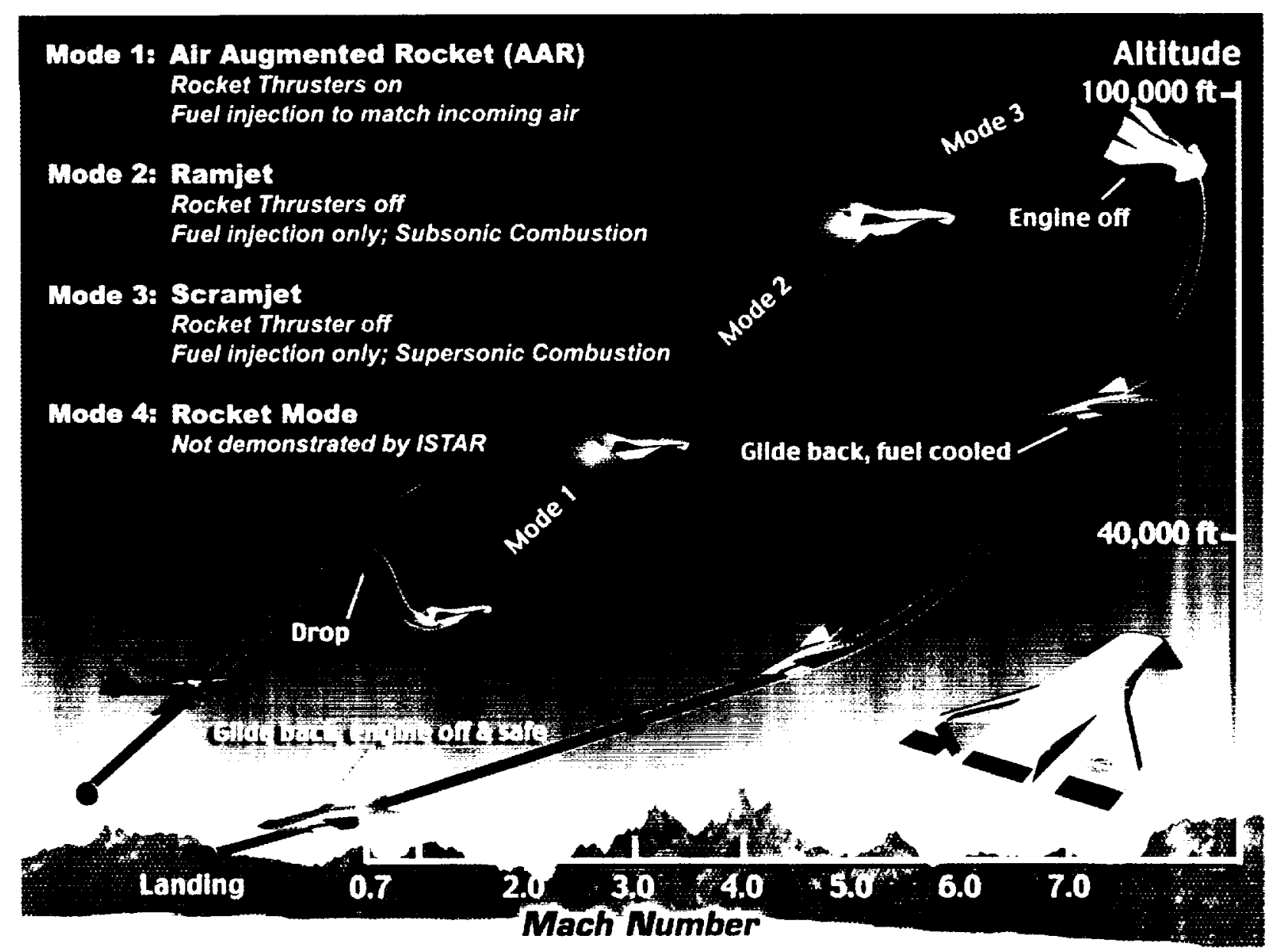

Figure 7: ISTAR Mission Profile. 


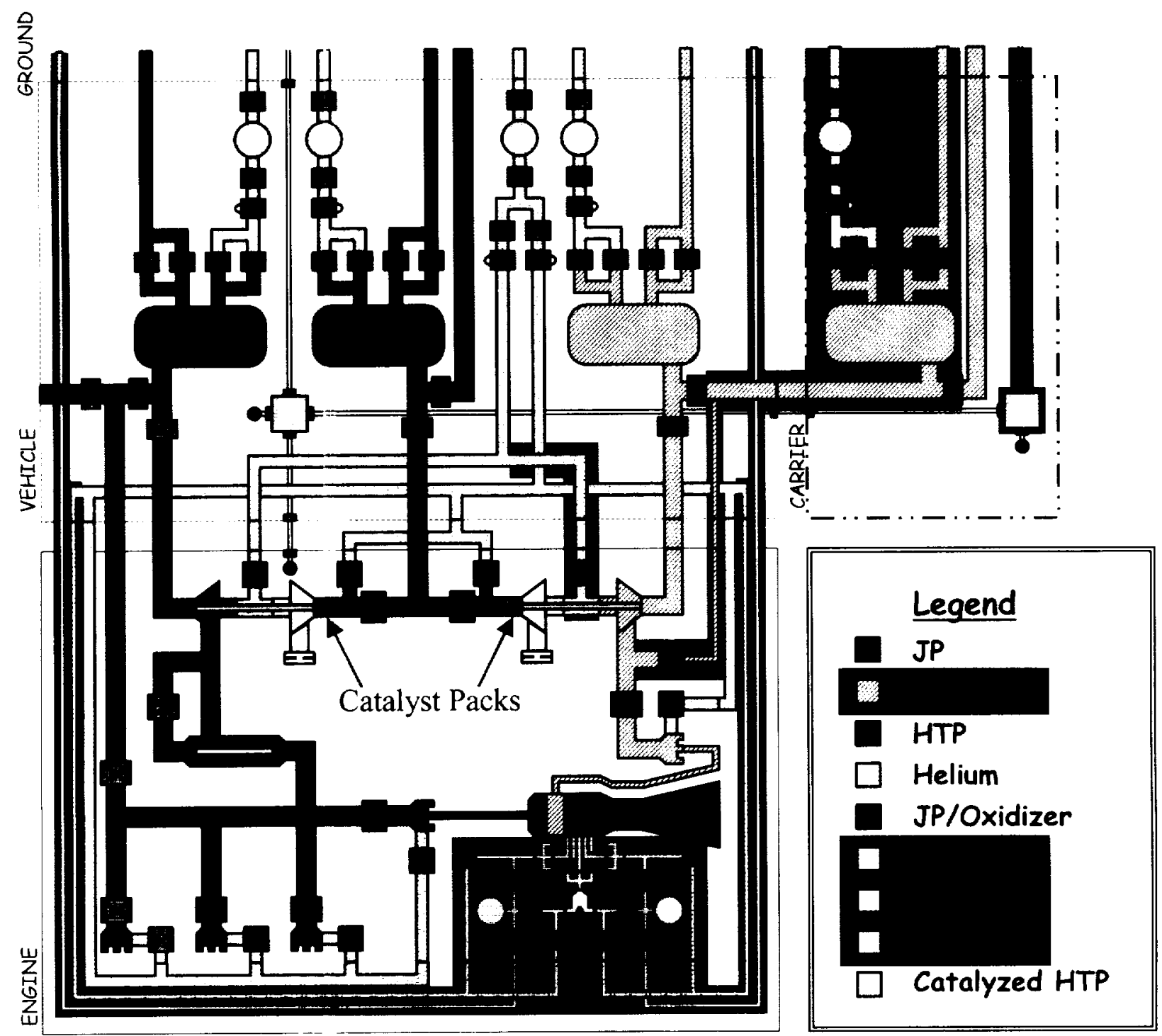

Figure 8: JP-7 / LOX propulsion system including the vehicle and carrier aircraft (B-52) note the red shaded areas are the additional components required by the system for this oxidizer. 


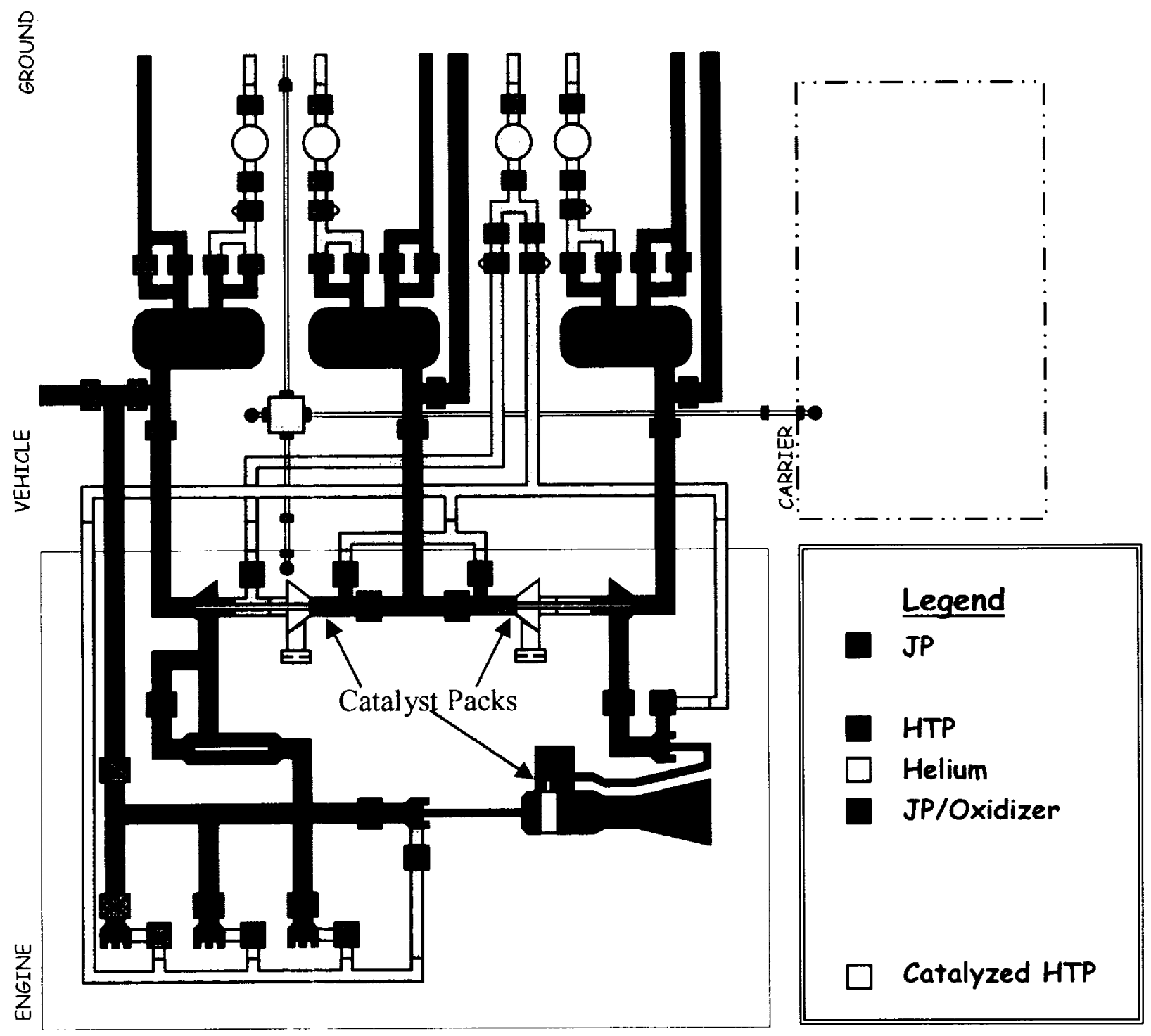

Figure 9: JP-7 / Hydrogen Peroxide propulsion system including the vehicle and carrier aircraft (B-52) note the red shaded areas are the additional components required by the system for this oxidizer. 


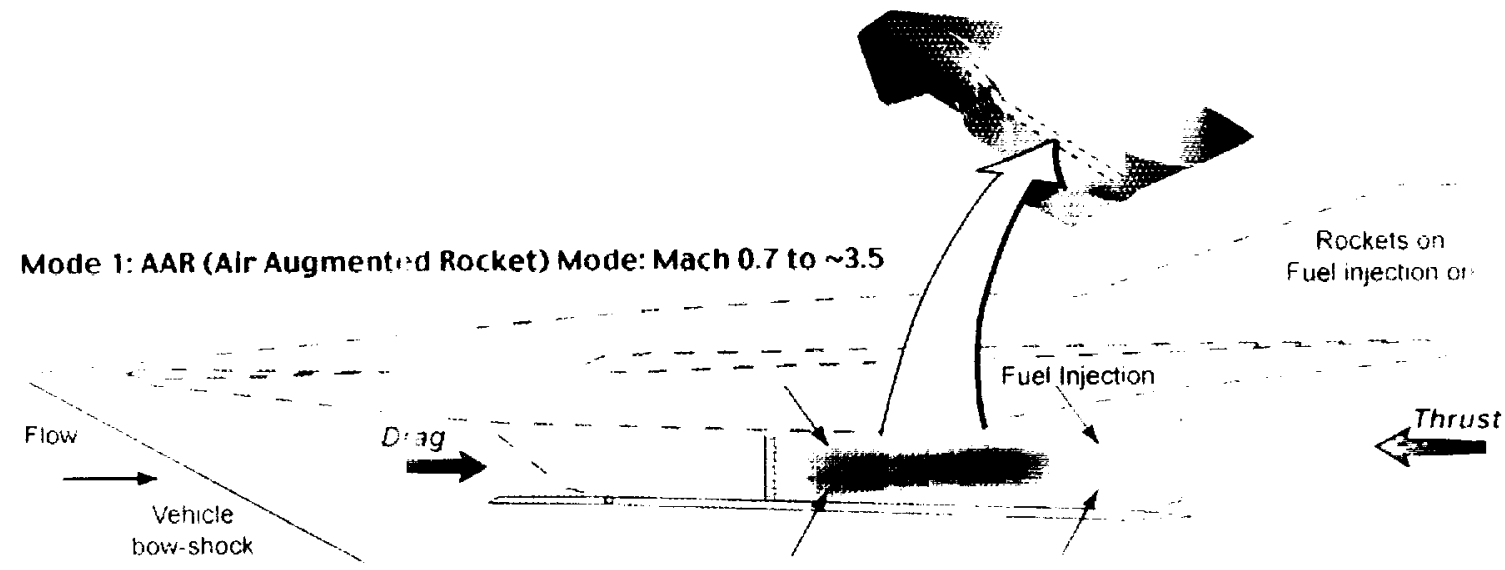

Mode 2: Ramjet Mode: Mac $1 \sim 3.5$ to Mach $\sim 6$

Rocket off Fuel injection only

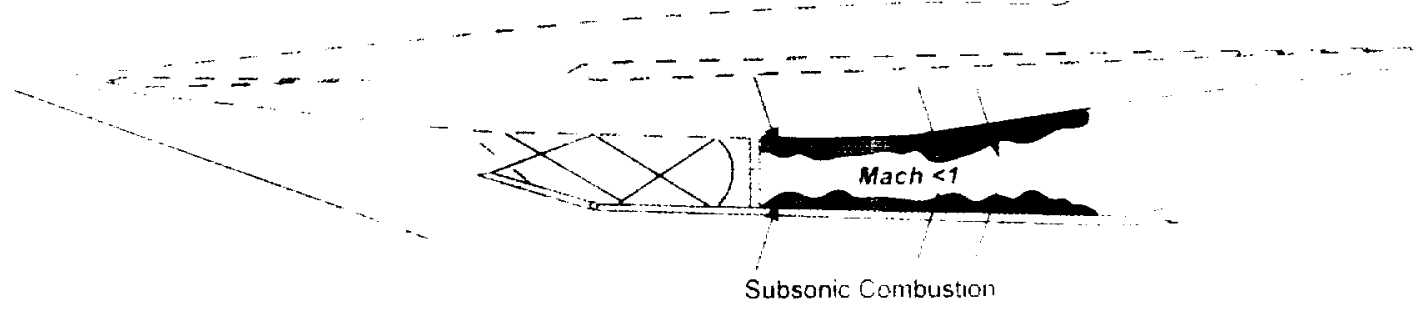

Mode 3: Scramjet Mode: Mach 6+

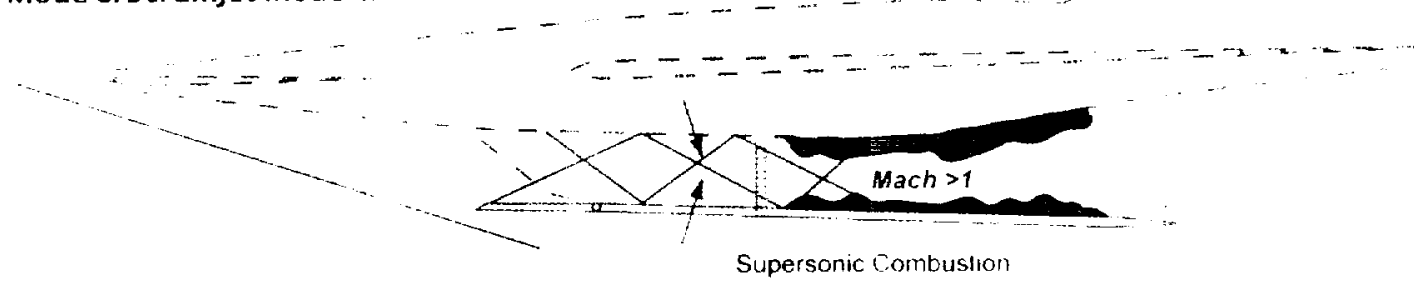

Mode 4: Rocket Mode: (Not demonstrated by ISTAR)

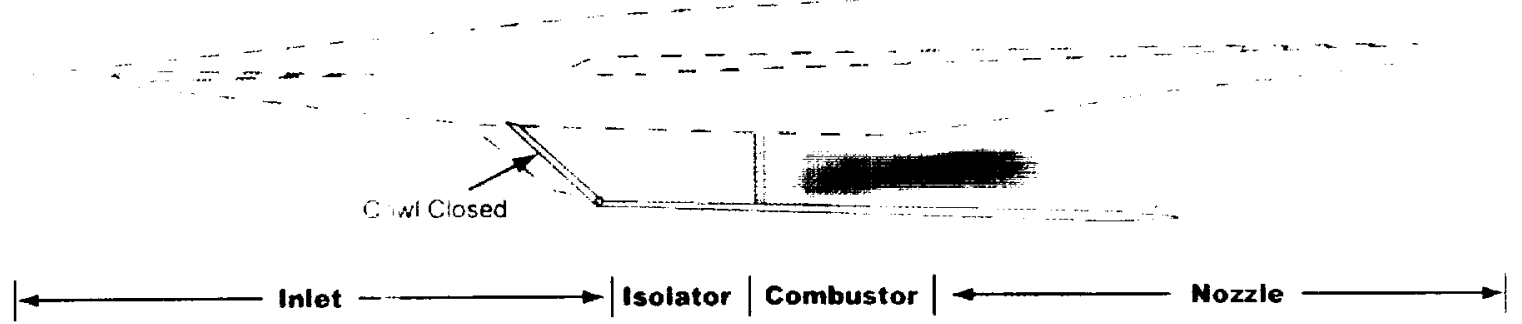

Figure 10: ISTAR engine operating modes. 